\title{
THEMA
}

\section{O ensino de língua materna através de paródias como ferramenta educacional}

\section{The teaching native language through parodies as educational tool}

Rafael de Souza Velasco ${ }^{1}$; Márcia Helena Sauaia Guimarães Rostas ${ }^{1}$; Cibele Trindade do Nascimento; Gabriel Barros ${ }^{1}$

\section{RESUMO}

O presente trabalho apresenta uma pesquisa empírica que visou refletir sobre a importância do ensino lúdico de língua portuguesa, através da implantação de paródias como ferramenta educacional na escola pública. Este trabalho teve por parâmetro a Lei 13.278/2016, que inclui as artes visuais, a dança, a música e o teatro nos currículos dos diversos níveis da educação básica. De base da legislação realizamos uma reflexão sobre o ensino de música na escola como um instrumento auxiliar do professor no processo de ensino e de aprendizagem dos alunos se apropriando da composição de paródias como recurso pedagógico na área da Linguagem. Defendemos a ideia de que o material criativo imprime dinamicidade ao conteúdo didático, promovendo interesse e despertando a curiosidade. A orientação metodológica utilizada é um estudo de caso de cunho descritivo qualitativo, que tem relação com a área de educação, da qual se refere, a contribuição de paródias musicais no ensino aprendizagem de alunos. A pesquisa foi realizada em duas escolas públicas da cidade de Pelotas, escolas estas situadas em diferentes localizações da cidade e uma sendo da Rede Estadual e outra da Rede Municipal. Os informantes foram os alunos do sétimo ano do Ensino Fundamental. Verificamos que a música, neste contexto, pode se configurar em um fortíssimo aliado mnemônico para a compreensão das regras de língua portuguesa, bem como para a formação do sujeito em virtude de se configurar em uma linguagem. A ludicidade se configura em um reforço pedagógico, ajudando os alunos na compreensão, memorização, oralidade, criatividade e, desta forma, resultando em um mecanismo de ensino e de aprendizagem mais eficaz.

Palavras-chave: Língua portuguesa; Gênero paródia; Recurso pedagógico; Ensino e aprendizagem.

\begin{abstract}
This paper presents an empirical research aimed at reflecting on the importance of Portuguese teaching in a playful way, through the implementation of parodies as an educational tool in the public school. This work was based on Law 13,278 / 2016, which includes the visual arts, dancing, music and acting in the curricula of the various levels of basic education. Based on the legislation we made a reflection on the music teaching in the school as an auxiliar instrument to teacher in the process of teaching and learning of the students appropriating the composition of parodies as a pedagogical resource in the Language field. We defend the idea that creative material gives dynamic to didactic content, promoting interest and arousing curiosity. The methodological orientation used is a qualitative descriptive study of case, which is related to the area of education, which refers to the contribution of musical parodies in the teaching of student learning. The research was carried out in two public schools of the city of Pelotas, schools located in different areas of the city and one being kept by the State Network and another by the Municipal Network. The informants were made seventh-year primary school
\end{abstract}

\footnotetext{
${ }^{1}$ IFSul - Instituto Federal de Educação, Ciência e Tecnologia Sul-rio-grandense, Pelotas/RS - Brasil.
} 
students. We have verified that music, in this context, can be configured in a strong mnemonic ally for the understanding of the rules of Portuguese language as well as for the formation of the subject by virtue of being configured in a language. The playfulness is configured in a pedagogical reinforcement, helping the students in the understanding, memorization, orally, creativity and, in this way, resulting in amore effective mechanism of teaching and learning.

Keywords: Portuguese language; Genre parodies; Pedagogical resource; Teaching and learning.

\section{INTRODUÇÃO}

Este estudo retrata a relevância de um ensino de língua materna descontraída, através de paródias como ferramenta educacional, auxiliando e dinamizando o ensino na escola pública. Os dados provenientes do estudo vieram de duas escolas públicas da cidade de Pelotas, Rio Grande do Sul. Foram observadas as aulas de português do sétimo ano das instituições. Partindo deste pressuposto, foi observado o ensino de gramática normativa respeitando aos Parâmetros Curriculares Nacionais e Referenciais Curriculares do RS em que se preconiza o estudo e o desenvolvimento artístico do aluno, que servem de subsídios para o exercício de conteúdos nos três níveis para a formação escolar dos educandos. Analisou-se a relação da aprendizagem do conteúdo proposto com a norma culta padrão e se os mesmos estavam compreendendo o que estava sendo ensinado. A inquietação aguçou ainda mais neste momento: como pode um ensino pautado no professor e não no aluno? O aprendiz deverá ser capaz de usar a variedade de linguagem certa, do modo certo, dentro de um dado discurso, mas como ele irá alcançar estes objetivos com um aprendizado normativo?

Estes fatores fazem emergir em caminhos para um aprendizado que o aluno consiga compreender sua própria língua. Vygotsky (2005) mostra-nos a importância das trocas de saberes e a relevância da interação social. Abordamos aspectos enunciados pelos documentos oficiais do governo e confrontamos este discurso com a realidade educacional brasileira, focalizando a formação de professores de língua materna e de línguas adicionais.

A grande preocupação após as observações das aulas foi: como fazer com que o aluno tenha interesse na aula de língua portuguesa? A motivação de ambos os envolvidos foi aproximar a música, por desempenhar um papel universal linguístico e aliado universal ao ensino de língua materna. Neste momento surgiu o segundo questionamento: como? Através da paródia como uma ferramenta didática. O viés metodológico teve como propósito averiguar o papel da música no processo de ensino aprendizagem de língua portuguesa.

O educador, nos dias atuais, trabalha com um aluno que interage, que dialoga, questiona e quer um aprendizado relevante e condizente com a sua realidade. Repensando nestes fatores o professor deveria relacionar os conhecimentos do aluno, sua cultura, seus novos gêneros de leitura a outras áreas de conhecimento. Desta maneira adotando diferentes recursos educacionais condizentes com seus alunos favorecendo, assim, um ensino eficaz e significativo.

Pensando na arte, a pintura, a escultura, a dança, a poesia, o teatro, a música, a batida ritmada, a vestimenta, os jogos e os corpos pintados fazem parte da história humana, da humanização do homo sapiens. Hoje, como em nenhum outro momento da história, a arte invade o cotidiano das pessoas. No entanto, as políticas de formação artísticas no Brasil ainda são tímidas, talvez a própria produção artística brasileira, apesar de seu vigor popular, seja relativamente pequena considerando o número de habitantes, a extensão geográfica e a variação cultural do país. 
Fundamentamos a nossa discussão nos documentos oficiais e instituições governamentais brasileiras, tanto federais (PCN), como estaduais (Referenciais Curriculares do RS), que abordam a questão. Conforme a Lei de Diretrizes e Bases da Educação Nacional (LDB), a disciplina é obrigatória no currículo escolar nos diversos níveis da Educação Básica. Discute-se, portanto, a formação artística do aluno no contexto escolar, isto é, o que a arte proporciona para alguém que, além de estudar português, história, geografia e matemática, quer se expressar livremente e criativamente nas suas práticas sociais, especialmente em relação aos aspectos culturais imateriais e materiais. Os resultados da análise mostram uma riqueza de objetivos apresentados nos documentos oficiais nacionais e estaduais, mas estes objetivos estão longe de serem atingidos nas escolas por causa de uma carência na formação de recursos profissionais.

Atualmente a sociedade procura um professor que vai além do modelo tradicional, um profissional recheado de estratégias, competências que vão muito além das mediações para o desenvolvimento da habilidade de ler e escrever. Exige-se do professor a habilidade de movimentar-se no mundo informacional e de como este mundo pode fornecer subsídios para a formação do cidadão brasileiro. Procura-se, portanto, um mestre que tenha na interdisciplinaridade uma de suas características mais marcantes.

Os autores do texto procuram distanciar-se da neutralidade e subjetividade conformistas e questionam a atitude adotada pela maioria das escolas, conforme sugerido nos próprios documentos governamentais, que endossam uma formação que visa a construção de "corpos" e mentes "dóceis", úteis para o sucesso econômico do país, filosofia educacional adotada pela maioria dos sistemas escolares, conforme evidenciado pelos documentos governamentais e pela experiência vivida pelos autores.

O trabalho foi realizado com o intuito de contribuir com os educadores das escolas e com outros espaços escolares. Mesmo que de forma breve, este projeto tem o intuito de auxiliar no ensino e educação de forma colaborativa e criativa, com uma compreensão teoricamente Marxista de cunho na tendência "crítico-social" das matérias, assuntos estes pertinentes para a educação abordados ao longo do texto.

\section{CAMINHOS PARA O ENSINO DE LÍNGUA PORTUGUESA}

A teoria de ensino e de aprendizagem contemporânea tem valorizado a participação ativa do aluno, de forma a tornar o processo de aprendizagem mais significativo para o aprendiz. Desta forma, em um primeiro momento, antes de apresentar as questões que balizaram esta pesquisa, apresentaremos um panorama teórico-descritivo sobre as relações professor-aluno na prática educativa. Com base neste panorama ficará mais fácil embasar as análises de diferentes práticas pedagógicas, em língua portuguesa e/ou qualquer outro componente curricular. Iniciamos destacando que a educação se configura, cria corpo, na medida em que existe um sujeito que aprende e outro que ensina, independentemente do local em que este processo ocorra.

Libâneo (1990) aponta que as principais tendências pedagógicas na educação brasileira se dividem em duas linhas de pensamento pedagógico: Liberais e Progressistas. As Tendências Liberais não têm relação com algo aberto ou democrático, faz menção, na verdade, à sociedade capitalista dividida em classes. Nesta concepção o aluno deve ser preparado para papéis sociais de acordo com as suas capacidades. Divide-se em: Tradicional, Renovadora Progressiva, Renovadora não diretiva (Escola 
Nova) e Tecnicista. Por outro lado, as Tendências Progressistas emergem de uma análise crítica das realidades sociais, das finalidades sociopolíticas da educação. Ao contrário das Liberais, estas tendências, não se enquadram com as ideias arraigadas pelo capitalismo. Ramifica-se em três correntes: Libertadora, Libertária e Histórico-Crítica.

Na Tendência Liberal Tradicional, o professor assume o papel de figura central e o aluno de receptor passivo dos conhecimentos. Há repetição e memorização de exercícios. Em seguida surge a Liberal Renovadora Progressiva caracterizada por centralizar no aluno a aprendizagem, considerado como ser ativo e curioso. Defende que o aluno "só irá aprender fazendo". Valoriza os experimentos, a pesquisa, a descoberta, o estudo do meio natural e social em que aprender é uma atividade de descoberta. O professor é, apenas, um facilitador. A Liberal Renovadora não diretiva (Escola Nova) tem na escola o papel de formador de atitudes. A preocupação maior está nos aspectos psicológicos, à revelia dos sociais ou pedagógicos. A aprendizagem tem que estar significativamente ligada as percepções do aluno que deve modificá-las. Centra-se unicamente no aluno. Na Tendência Liberal Tecnicista, também conhecida como behaviorista, o aluno é visto como depositário passivo dos conhecimentos, que devem ser acumulados por associações. O professor é responsável por este depósito e possui uma prática extremamente controlada. A educação articula-se com o sistema produtivo formando mão de obra especializada para o mercado de trabalho. (LIBÂNEO, 1990: p. 2225)

Na Tendência Progressista Libertadora atrela a educação à luta e organização da classe oprimida. Busca além da transformação social, o desenvolvimento de uma consciência crítica diante de sua organização de classe. O professor atua ao lado dos alunos coordenando as atividades e centralizando a discussão em torno de temas sociais e políticos. Na Tendência Progressista Libertária defende-se que somente o vivido pelo aluno é acionado e utilizado, quando necessário, em novas situações. Com base nisso o saber sistematizado só terá importância se houver um uso prático. Os conteúdos são disponibilizados, mas não são exigidos pelos alunos e o professor assume o papel de conselheiro à disposição do aluno. Na Tendência Progressista "Crítico-social dos conteúdos" aguça a prioridade de focar os conteúdos às realidades sociais, e ao contexto histórico. Configura-se como mediadora entre conteúdos e alunos. O processo de ensino e de aprendizagem tem como centro o aluno e o conhecimento é construído pela experiência pessoal e subjetiva. (LIBÂNEO, 1990: p. 26-30)

Nossa pesquisa centra-se em uma prática de ensino de língua portuguesa que tem como foco a aprendizagem dos conteúdos a partir de conteúdos que façam sentido para o aluno. Nossa perspectiva teórica, de fundo marxista, pauta-se no viés da Tendência Progressista "Crítico-social dos conteúdos" (LIBÂNEO, 1990: p. 29)

Baseamo-nos, ainda, nos Parâmetros Curriculares Nacionais (PCN) de língua portuguesa (BRASIL, 1997) e também nas indicações dos PCN de Arte (BRASIL: 1998) e na Lei no 11.769/2008 que institui o ensino de música nas escolas (BRASIL: 2008). Nossas atividades se configuraram a partir do gênero paródia instrumentalizando as práticas de linguagem em sala de aula.

A escolha do gênero se deu em virtude da interseção com ele ser bastante comum nas aulas de língua materna ou estrangeira. Observamos que, muitas vezes, na utilização deste gênero em atividades pedagógicas os aspectos relacionados à linguagem musical não são adolescidos, muitas vezes em função da falta de instrumentos didáticos apropriados. 
As questões que balizaram esta pesquisa partem de uma inquietação pessoal e atual: Como realizar uma prática educativa estimulante, que os alunos gostem e sintam-se motivados? Que aborde os conteúdos às realidades sociais, e ao contexto histórico? Como trabalhar pedagogicamente conteúdos de língua portuguesa de maneira leve e descontraída? Os PCN para o Ensino Médio enfatizam que "[a] aprendizagem significativa pressupõe a existência de um referencial que permita aos alunos identificar e se identificar com as questões propostas." (BRASIL, 1999, p. 104)

A língua portuguesa, enquanto componente curricular, deve ser vislumbrada, dentro do ambiente escolar como linguagem. Mas o que é linguagem? Definindo linguagem, dentro do Círculo de Bakhtin, ressignificamos como produção de sentidos no processo enunciativo. Sendo assim, a linguagem se configura enquanto" [...] as formas do signo [que] são condicionadas tanto pela organização social [dos] indivíduos como pelas condições em que a interação acontece. Uma modificação destas formas ocasiona [em] uma modificação do signo. " (BAKHTIN, 1999: 44).

A linguagem faz parte das memórias e do desenvolvimento dos indivíduos. Vygotsky (2005) preocupava-se em entender a relação entre as ideias que as pessoas desenvolvem e o que dizem ou escrevem. Com base em suas pesquisas empíricas e experiências pessoais chegou a conclusão que a " [...] estrutura da língua que uma pessoa fala influencia a maneira com que esta pessoa percebe 0 universo ..." (p.5). Arriscamos afirmar, baseados no autor, que o pensamento e a linguagem formam o caráter do indivíduo e o desenvolvimento cognitivo, incluindo o desenvolvimento da língua, surge como um resultado da interação social.

Os PCN (BRASIL, 1996) é criado com o intuito de subsidiar os professores, do ponto de vista pedagógico e conceitual, na preparação de suas aulas em todas as series e disciplinas escolares. Segundo o PCN de língua portuguesa (BRASIL, 1997) o aprendizado ocorre em três esferas: aluno, língua e ensino. Porém ensinar língua portuguesa não é somente ensinar gramática para o aluno, a linguagem tem um caráter único e importante para o aprendiz.

Nos Referenciais Curriculares do Rio Grande do Sul contém uma parte destinada as artes visuais, música, teatro e dança, denominada de disciplinas artísticas. (RIO GRANDE DO SUL, 2009). O documento busca elucidar a questão de que as práticas artísticas são parte da cultura e da construção da humanidade e são tão importantes quantas outras áreas do conhecimento. A questão da interdisciplinaridade da arte também é destacada, pois o ensino dela constitui uma das formas do ser humano se relacionar com o mundo, sendo assim pode estar em parceria para a aquisição de conhecimento em outras áreas, como no caso do ensino de língua portuguesa.

\section{METODOLOGIA}

Levando em conta o contexto de nossa pesquisa, o problema investigado, e os sujeitos nela envolvidos, optamos pelo estudo de caso, por considerar essa abordagem uma estratégia relevante no que se refere à apuração dos dados da pesquisa e aos elementos que surgiram em relação à problemática pesquisada.

Yin (2015, p. 17) aponta que o estudo de caso é uma investigação empírica que investiga o fenômeno (o "caso") em profundidade e em seu contexto de mundo real, especialmente quando os limites entre o fenômeno e o contexto puderem não ser claramente evidentes. Avaliar a realidade de um estudo desta natureza que envolve um fenômeno educacional implica levar em consideração uma série de 
elementos que constituem o ambiente escolar: o contexto no qual a escola está inserida, as pessoas que fazem parte deste ambiente: professor e aluno interpelados pela linguagem e situados historicamente.

Uma investigação, nessa perspectiva, requer, além do rigor do método, uma minuciosa análise dos agentes que compõem este universo, o da abordagem qualitativa. A orientação metodológica adotada é o estudo de caso de cunho descritivo qualitativo, que tem relação com a área de educação, da qual se refere, a contribuição de paródias musicais no ensino aprendizagem de alunos.

A abordagem qualitativa "[...] privilegia a análise de micro processos, através do estudo das ações sociais individuais e grupais, realizando um exame intensivo dos dados." (MARTINS, 2004, p.289)

Os sujeitos da pesquisa são 44 alunos de duas turmas do 70 ano do ensino fundamental de duas escolas municipais localizadas na cidade de Pelotas, no sul do estado do Rio Grande do Sul: Escola Pública do Estado (Turma 1) - 20 alunos e Escola Pública Municipal (Turma 2) - 24 alunos, perfazendo um total de 44 informantes.

A escolha pelo sétimo ano, na seleção dos sujeitos, se justifica pelo fato de que esses alunos, supostamente, já possuem algumas competências e habilidades construídas ao longo de todo o percurso do ensino fundamental, ou seja, pressupõe-se que já tenham desenvolvido as competências e as habilidades de leitores mais proficientes do que os das séries iniciais dos anos finais dessa etapa.

As atividades, em sala de aula com os alunos, foram desenvolvidas durante um mês com periodicidade de2 (dois) períodos de 50 (cinquenta) minutos, em cada turma, por semana. Foram, portanto, 5 encontros totalizando 10 (dez) períodos.

Precedendo as atividades desenvolvidas em sala de aula, foram realizadas visitas a escola e observação orientada no cotidiano formativo do professor responsável pelo componente Curricular, análise do planejamento e observação da execução em sala de aula. É importante destacar que todo o percurso de observação e aplicação de atividade teve a anuência da escola e do professor.

Nas duas escolas percebemos o quanto os alunos, diante dos inúmeros atrativos extra-classe e extraaula, ficam dispersos. Observamos, inclusive, que em diversos momentos há uma ausência, não física, do ambiente de sala de aula. É por isso que Charlot (2005) adianta que o aluno:

[...] em sua vida cotidiana fora da escola, [...] têm práticas, representações, valores que a escola desconhece ou não reconhece [...] Consequentemente, a cultura que a escola Ihes impõe não faz sentido para eles e, ao mesmo tempo, esses jovens não vão bem na escola [...]. (CHARLOT, 2005, p. 136).

Durante as observações fizemos, com base no planejamento docente, um levantamento dos conteúdos que estavam sendo trabalhados. Observamos, inclusive, a metodologia, a fim de perceber o poder de compreensão e abstração dos alunos.

Na segunda etapa da pesquisa, em que assumimos a regência, escolhemos um conteúdo já contemplado pelos docentes de ambas as escolas: Aposto e Vocativo. No primeiro encontro aplicamos uma avaliação diagnóstica a fim de realizar uma sondagem inicial. A composição do documento abrangia duas assertivas: 1) Manoel, português casado com minha prima, é um ótimo engenheiro. 2) 
Amigos, vamos ao cinema hoje? Com base nelas foi questionado qual delas representava um exemplo de Vocativo e qual representava um exemplo de Aposto.

O resultado da sondagem nos forneceu o grau de domínio de conteúdo pelos estudantes acerca da matéria didática estudada. A Turma $1 \mathrm{com} 20$ alunos presentes produziu o seguinte resultado: 8 acertos e 12 erros. Ou seja, apenas 40\% tinham domínio do conteúdo, já trabalhado em sala de aula. A Turma 2, com resultado semelhante, com 24 alunos presentes, teve por resultado: 10 acertos e 14 erros. Ou seja, apenas $41,6 \%$ com domínio de conteúdo.

De posse do resultado planejamos uma nova atividade com o conteúdo Aposto e Vocativo. No encontro seguinte apresentamos uma paródia, pré-elaborada pela equipe de pesquisadores, abordando os tópicos pertinentes ao conteúdo didático.

Colocamos os alunos em círculo, distribuímos a letra construída na forma de Paródia da música In The Wall (Pink Floyd), letrada com a regra de Português que justifica a diferenciação entre o que é aposto e o que é vocativo. Acompanhados de um violão e instrumentos de percussão entoamos a assertiva " $O$ aposto e o Vocativo... são parecidos na Oração...esse indica um chamamento... e o outro uma explicação... Termo Acessório é aposto na Oração".

A utilização da paródia em sala de aula não é um meio pedagógico convencional, mas sim uma metodologia alternativa, utilizando o lúdico como fonte de inspiração, trabalhando uma estratégia inovadora para conteúdos tão sóbrios como os que tratam a disciplina de língua portuguesa. Simões (2012) afirma que nas últimas décadas as teorias de ensino e aprendizagem buscam a participação ativa do aluno em sala de aula, tornando a aprendizagem significativa e estimulante.

Os alunos ficaram muito empolgados a ponto de quererem repetir várias vezes a canção. Tal fato ocorreu da mesma forma nas duas escolas, e mais, o grau de envolvimento e empolgação era latente.

De acordo com Charlot (2000, p.18) "[...] a escola não é apenas um lugar que recebe aluno dotados desta ou daquelas relações com o(s) saber(es), mas é também um lugar que induz a relações com o(s) saber(es)". Esta abordagem, em que é usada uma dinâmica (paródia) como recurso didático, vem ao encontro da escola como um sinônimo de lugar significativo para a vida dos alunos. $A$ constituição de diversas relações com os saberes com o objetivo de obter compreensão, fazendo dos conteúdos proposições cheias de sentidos e voltadas para a realidade, assim como é a música em suas vidas.

Este fato é tão interessante que podíamos observar que todos os alunos participavam ativamente daquela atividade e ocupavam aquele espaço físico. No encontro seguinte apresentamos uma nova atividade avaliativa com o mesmo conteúdo. O resultado nos surpreendeu, após a atividade com a utilização da Paródia, na turma 1, dos 20 alunos, 18 haviam assimilado a regra gramatical após a canção ter sido apresentada por 3 vezes em sala de aula, correspondendo a 90\%, apenas 2 alunos não obtiveram êxito. Na turma 2, para nossa surpresa, o resultado foi ainda melhor: dos 24 alunos presentes, $100 \%$ obtive êxito na atividade.

A atividade foi acompanhada pelos docentes responsáveis pela disciplina. Ao serem consultados acerca da intervenção tanto o "Professor A", responsável pela Turma 1, como o "Professor B", responsável pela Turma 2, avaliaram a atividade como "criativa e motivadora" e admitiram a 
necessidade de buscar novas estratégias lúdicas para obter melhores resultados com os alunos na compreensão do conteúdo de língua portuguesa.

Sendo assim, diante da nossa atividade, observamos que:

[...] a razão [...] da avaliação [...] não é classificação ou a retenção de alunos, mas a identificação do estágio de compreensão e assimilação do saber pelo educando, junto com as dificuldades que este encontra, bem como os fatores que determinam tais dificuldades, com vistas à adoção de medidas corretivas da ação. (PARO, 2001, p.3940)

Observamos que muitos professores se utilizam de testes e provas, adotando modelos tradicionais, que traduzem no sujeito aprendiz um status de bom ou de mau aluno, classificando-o e emitindo juízos de valor sobre àquilo que acaba sendo denominado de (in)capacidade.

Por fim, destacamos que para que haja aprendizagem é necessário investimento do sujeito. Porém o investimento só ocorre se houver sentido. Charlot (2000, p.54) refuta que "[...] ninguém poderá educar-me se eu não consentir de alguma maneira, se eu não colaborar, uma educação é impossível, se o sujeito a ser educado não investe pessoalmente no processo que o educa". Resta, portanto, saber como o professor poderá investir no sujeito de tal forma que ele alcance, em seus alunos, a aprendizagem.

\section{CONSIDERAÇÕES FINAIS}

Esta investigação foi motivada por uma inquietação, que procuramos responder, através da aplicação planejada de uma atividade lúdica abordando um conteúdo didático. - Como realizar uma prática educativa estimulante, que os alunos gostem, que sintam-se motivados e atrelem os conteúdos às realidades sociais, e ao contexto histórico? Verificamos, após a realização da atividade com os alunos da $7^{a}$ série das duas escolas municipais, em que as aulas de língua portuguesa ganharam um reforço pedagógico, o grau de aproveitamento dos alunos ampliou significativamente, alcançando quase a totalidade.

Conversando com os alunos eles alegaram ter compreendido de forma clara e objetiva o conteúdo, um dos alunos da turma 1 declarou que " [...] se eu fizer uma avaliação no fim do ano sobre esse assunto eu sei a letra da canção e, desta forma, acertarei tudo. Sabe porque? Eu aprendi!" Foi comovente e enriquecedor ver a empolgação do aluno e perceber que a música se configurou como um importante aliado para a aprendizagem.

Bréscia (2003), afirma que a música está presente em quase todas as manifestações sociais e pessoais do indivíduo desde os tempos mais antigos, e se configura como uma linguagem de muitos significados. Essa linguagem transforma-se em recurso didático na medida em que é chamada a promover o desenvolvimento de conteúdos programáticos a partir do processo de transformação de conceitos espontâneos em conceitos científicos.

Ferreira (2008) observa que o campo da música é muito fértil e de fácil assimilação e, desta forma, muito útil para a atividade docente. Pode ser facilmente utilizado por um profissional que intenta modificar, dinamizar e ter mais eficiência no processo de aprendizagem de seus alunos a partir da forma como ele explica o conteúdo lecionado. 
A segunda inquietação: Como trabalhar pedagogicamente conteúdos de língua portuguesa de maneira leve e descontraída? A atividade com a música configurou-se em uma prática dinâmica e alegre pelos alunos ajudando-os na compreensão e na memorização de um determinado conteúdo. Poderíamos ampliar os resultados afirmando que atividades desta natureza contribuem para a oralidade, para a criatividade e, consequentemente, para um processo de ensino e de aprendizagem mais significativo para os estudantes.

O resultado aponta que a abordagem alternativa, neste caso representado por meio da utilização da Paródia com o conteúdo didático, funciona como um ótimo recurso pedagógico. A atividade aperfeiçoou a percepção cognitiva dos alunos procedendo em um aumento de concentração e, consequentemente, aprendizagem.

Silveira e Kiouranis (2008) destacam que o uso de paródias não pode ser uma atividade de simples memorização, mas reportar-se à possibilidade de situar a música a realidade dos estudantes, problematizando conteúdos e realidade. Ferreira (2008) enfatiza que ao longo da existência do ser humano, sempre foi bastante utilizada à prática de associar qualquer disciplina à música, demonstrando muitas potencialidades como fator auxiliar no aprendizado, despertando e desenvolvendo nos alunos sensibilidades mais aguçadas na observação de questões próprias, nos conteúdos curriculares.

Com esta pesquisa, não tivemos a pretensão de solucionar os problemas que foram detectados com relação a aprendizagem dos alunos, mas a intenção de colaborar com questões pertinentes ao planejamento docente e a utilização da música como alternativa pedagógica.

Dessa forma, num sentido pouco conclusivo, é fundamental que o professor redimensione seu trabalho refletindo sobre as suas práticas a serviço da aprendizagem dos alunos. Por fim percebemos que a ferramenta musical, pode se configurar em um excelente recurso didático-pedagógico em sala de aula, auxiliando e dinamizando o ensino de língua portuguesa, nas escolas públicas do município de Pelotas-RS.

\section{REFERÊNCIAS}

BRASIL. Lei de Diretrizes e Bases da Educação Nacional n 9.394, de 20 de dezembro de 1996. Brasília: MEC, 1996.

BRASIL. PCN - Parâmetros Curriculares Nacionais. Brasília, MEC: 1996

BRASIL. Parâmetros Curriculares Nacionais: ensino médio. Brasília, MEC: 1999. Edição em volume único.

BRASIL. Parâmetros Curriculares Nacionais: língua portuguesa. Ministério da Educação e do Desporto. Secretaria de Educação Fundamental: Brasília, 1997.

BRASIL. Parâmetros curriculares nacionais: arte. Ministério da Educação e do Desporto. Secretaria de Educação Fundamental. Brasília, 1998.

BRASIL. Lei no 11.769/2008. Altera a lei no 9.394/96, de 20 de dezembro de 1996, Lei de Diretrizes e Bases da Educação para dispor sobre a obrigatoriedade do ensino de música na educação básica. Presidência da República. Brasília, 2008. 
BRÉSCIA, Vera Lúcia Pessagno. Educação Musical: bases psicológicas e ação preventiva. São Paulo: Átomo, 2003.

CHARLOT, Bernard. Relação com o saber, formação dos professores e globalização: questões para a educação hoje. Porto Alegre: Artmed, 2005.

CHARLOT, Bernard. Da relação com o saber: elementos para uma teoria. Porto Alegre: Artes Médicas, 2000.

FERREIRA, M. Como usar a música na sala de aula. 7. ed. São Paulo: Contexto, 2008.

LIBÂNEO, José Carlos. Democratização da Escola Pública. São Paulo: Loyola, 1990.

MARTINS, Maria Helena. O que é leitura. São Paulo: Editora Brasiliense, 2004.

PARO Vitor Henrique. Reprovação Escolar: renúncia à educação. São Paulo: Xamã, 2001

RIO GRANDE DO SUL. Secretaria de Estado de Educação. Referenciais curriculares do Estado do Rio Grande do Sul - Lições do Rio Grande: linguagens códigos e suas tecnologias: arte e educação física. $\quad$ v. $2 . \quad$ Porto Alegre: $2009 . \quad$ Disponível em: <http://www.educacao.rs.gov.br/dados/refer curric vol2.pdf> . Acesso em: nov./2010.

SILVEIRA, M. P.; KIOURANIS, N. M. M. A música e o ensino de química. Química nova na escola, n. 28, p. 28-31, 2008.

SIMÕES, A. O Gênero Paródia em Aulas de Língua Portuguesa: Uma abordagem criativa entre letra e música. SIELP. Volume 2, Número 1. Uberlândia: EDUFU, 2012 Disponível em: http://www.ileel.ufu.br/anaisdosielp/wp-content/uploads/2014/06/volume_2_artigo_006. pdf. Acesso em 22 out. 2015.

VYGOTSKY, L. S. Pensamento e linguagem. São Paulo: Editora Martins Fontes, 3a Ed., 2005.

YIN, Robert. Estudo de Caso - Planejamento e Métodos. 5a ed. Porto Alegre: Bookman, 2015. 